\title{
The fate of leachate of pharmaceuticals like amoxicillin, ibuprofen and caffeine in the soil using soil columns
}

\author{
Shehdeh Jodeh a,*, Halimeh Staiti b, Marwan Haddad b, Tamara Renno c, \\ Abdelnaser Zaid c, Nidal Jaradat ${ }^{c}$ and Maher Kharoaf ${ }^{d}$ \\ a Chemistry Department, An-Najah National University, Nablus, 11347, Palestine \\ ${ }^{\mathrm{b}}$ Water and Environmental Institute, An-Najah National University, Nablus, 11347, Palestine \\ c Pharmacy Department, An-Najah National University, Nablus, 11347, Palestine \\ d Jerusalem Pharmaceutical Company, Ramallah, 11347, Palestine \\ ${ }^{*}$ Corresponding author at: Chemistry Department, An-Najah National University, Nablus, 11347, Palestine. \\ Tel.: +970.59.959049; Fax: +970.59.2345982. E-mail address: sjodeh@najah.edu (S. Jodeh).
}

\section{ARTICLE INFORMATION}

Received: 30 October 2012

Accepted: 07 November 2012

Online: 31 December 2012

\section{KEYWORDS}

\section{Kinetics}

Leachate

Adsorption

Pharmaceuticals

Chemical oxygen demand (COD)

Biochemical oxygen demand (BOD)

\begin{abstract}
From an environmental engineering point of view, pharmaceuticals such as antibiotics are a group of man-made chemicals of concern entering the environment in concentrations at which, the health effects are unknown. The problem that may be created by the presence of antibiotics at low concentrations in the environment is the development of antibiotic resistant microorganisms. In this study, three pharmaceutical drugs manufactured in Palestine were studied in waste water and their adsorption in agriculture soil was studied using soil columns. During the study of soil columns, it was noted that the concentration of caffeine in leachate was higher than that of ibuprofen and amoxicillin, as caffeine has higher aqueous solubility. Ibuprofen and amoxicillin were present in leachate with very small concentrations, due to their degradation and decomposition into other substances that may be harmful, and affect the natural properties of soil, groundwater and human health. The decomposition percentages of the pharmaceuticals in the soil columns were $97.82,97.88$ and $86.52 \%$ for amoxicillin, ibuprofen and caffeine for one year's study, respectively. For the fifteen years, the decomposition percentages were $94.04,96.60$ and $93.70 \%$ for amoxicillin, ibuprofen and caffeine, respectively.
\end{abstract}

\section{Introduction}

water as resources become scarcer [8]. The use of wastewater, often untreated, to irrigate soils occurs widely in less developed countries and has done so for many years [9].

In different countries including Palestine, drugs and their metabolites have been repeatedly detected in ground and surface waters and occasionally in drinking water [10-12]. After intake, the drugs or metabolites are excreted and reach the sewage plant through the sewage system. Because of the absence of any specific absorption or degradation system, drugs and their metabolites reach the pond water and ground water [10-12]. Further sources include the improper disposal of residual or outdated drugs through the sewage systems of private households, and the improper disposal on dumps, which possibly bypasses the sewage plant.

In general, most pharmaceuticals in the environment are the result of human excretion but also pharmaceuticals may be found in low concentrations in landfill leachate, discharged to wastewater treatment plants. Although the science is limited, this might suggest that landfill disposal of pharmaceuticals may be a low-risk practice. Wastewater treatment plants are not designed to remove pharmaceuticals, so this also can be viewed as a minor pathway by which pharmaceuticals reach the environment. According to a 2007 report [13] prepared for the Oregon Association of Clean Water Agencies, only a few studies prior to that date had examined concentrations of pharmaceutical compounds in leachate from lined landfills and all of those studies focused on landfills in countries other than the U.S. [14]. The report concluded that theoretical calculations and becoming more common for wastewater effluents in developed countries as a tertiary treatment process and a way of reusing 
field data suggest that drugs disposed of in municipal solid waste landfills contribute only a small fraction $(<1 \%)$ of the total load of pharmaceutical compounds discharged to surface water via municipal wastewater treatment plants and landfill leachate treatment systems. In most developed countries, landfills are now equipped with engineered liners and leachate collection systems in order to minimize the adverse impacts of leachate on the surrounding environment [15].

In this study three selected pharmaceutical products manufactured by major drug companies in Palestine were chosen, to study their presence in the wastewater of those companies and to study their leachate in soil using a plastic pipes columns filled with agriculture soil. The objective of this study is to understand the fate of those drugs, waste penetrating groundwater through soil using soil columns and add different concentrations of those drugs in the columns and collect the leachates out of those columns. This will be explained in details in the methods and materials section.

\section{Experimental}

The research experimental work basically depends on determining the concentration of residues of amoxicillin, ibuprofen, and caffeine (Scheme 1) versus time in soil, and leachate, which is considered by three terms, Zero-term, shortterm (one year), and long-term concentration (fifteen years) which all of which will be explained later.



Amoxicillin

Amoxicillin
$(2 S, 5 R, 6 R)-6-\{[(2 R)-2$-amino-2-(4-hydroxyphenyl)-acetyl $]$ amino $\}-3,3-$ dimethyl-7-oxo-4-thia-1-azabicyclo[3.2.0]heptane-2-carboxylic acid



Ibuprofen

$(R S)$-2-(4-(2-methylpropyl)phenyl)propanoic acid

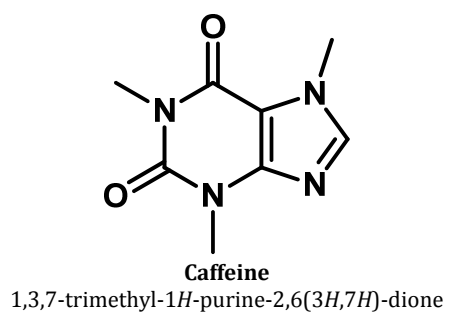

Scheme 1

\subsection{Instrumentation}

High-Performance Liquid Chromatography (HPLC) consisted of a Waters Millipore (Bedford, MA) 6000A pump, SpectraPhysics (San Jose, CA) 3000A automatic injector with column heater, Waters/Millipore 440 dual fixed wavelength UV detector, Spectra Physics Winner data collection system with 4270 integrator and a column of Whatman $10 \mathrm{~cm}$ Partishere 5
C18 $\mu \mathrm{m}$ packing. The injection volume used was $10 \mu \mathrm{L}$ with a flow rate of $1 \mathrm{~mL} / \mathrm{min}$. Data was collected at 254, 230 and 256 $\mathrm{nm}$ for ibuprofen, amoxicillin, and caffeine, respectively at 2.5 points/second. Column temperature was regulated at $30{ }^{\circ} \mathrm{C}$, a few degrees above ambient temperature to stabilize retention time.

\subsection{Soil column preparation}

Seven columns of Polyvinyl chloride (PVC) $(15 \times 100 \mathrm{~cm})$ were prepared after filling them with sieved soil $<63 \mathrm{~mm}$. All of the columns were prepared by adding distilled water through them to insure that there are no gaps or spaces between the soil pieces. The first column was used as blank which had only soil and distilled water. The second column represented one year's expectation to see what will happen to the drug after it was adsorbed by soil. The second and third columns were polluted using amoxicillin contained at $50 \mathrm{mg} / \mathrm{L}$, solution containing $0.2034 \mathrm{~g}$ for one year and $3.054 \mathrm{~g}$ in $4.0 \mathrm{~L}$ for $15-$ years. Usually we add 4 liters of $50 \mathrm{mg} / \mathrm{L}$ of amoxicillin to the soil in the column to study the adsorption and leachate. The third column was used for the study of the adsorption for 15 years, which is basically adding 4 liters of $750 \mathrm{mg} / \mathrm{L}$ of amoxicillin and studying the adsorption and leachate. The fourth column was polluted with Ibuprofen; a solution containing $0.2034 \mathrm{~g}$ of Ibuprofen in a $4.0 \mathrm{~L}$ container with 50 $\mathrm{mg} / \mathrm{L}$ was prepared and added to the column, therefore it was labeled (ibuprofen one-year). The fifth column contained 3.054 $\mathrm{g}$ of Ibuprofen powder in $4.0 \mathrm{~L}$, contained $150 \mathrm{mg} / \mathrm{L}$ of ibuprofen and labeled ibuprofen 15 years. These labels are related with the study of the fate of pharmaceuticals in one year and 15 years, respectively. The sixth and seventh columns were polluted using caffeine of $50 \mathrm{mg} / \mathrm{L}$ solutions containing $0.2034 \mathrm{~g}$ for one year, and $3.054 \mathrm{~g}$ for 15 -years. After the addition of pharmaceuticals to the columns, soil columns were left for $24 \mathrm{hrs}$ to ensure a complete adsorption process on soil. Of course each column was prepared by adding distilled water before addition drugs to wet the columns and make sure that there was no air between soil granules and the water running smoothly in the columns.

In Palestine it rains an average of 43 days a year and we used this number to add the drugs to column 43 times and we collected the leachate every 72 hours for HPLC analysis. The leachates were centrifuged at $1100 \mathrm{~g}$ for $20 \mathrm{~min}$, and then, the supernatant solution was decanted, filtered through $0.45 \mu \mathrm{m}$ Acrodisk filters, and stored at $4{ }^{\circ} \mathrm{C}$ before analysis using HPLC. At the end of the experiment, each soil column was cut into eight parts $(0-25,25-50,50-75,75-100,100-125,125-150$, $150-175,175-200 \mathrm{~cm}$ ).

The soil was taken out and extracted with double-deionized water (DDW) at $18 \mathrm{M} \Omega$ resistivity. All pharmaceuticals and chemicals were purchased from the Sun Company in Palestine and all chemicals with of very high purity. The other pharmaceutical materials (samples for studies) were manufactured in Palestine (Beir Zeit, Dar El-shefa and Jerusalem Pharmaceutical Companies).

All standard solutions used in the experiment were analytical reagent grade or of extra pure quality unless otherwise indicated. All glassware and plastic containers were soaked overnight in $10 \%$ nitric acid and rinsed with DDW before they were used for analysis.

\subsection{HPLC scanning of amoxicillin}

For detection the wavelength of pharmaceuticals using UV detector, chemicals and reagents like acetonitrile solution, monobasic potassium phosphate, sodium hydroxide, distilled water, and the pharmaceuticals were used. In this experiment three solutions were prepared:

Mobile phase solution prepared from a diluent and acetonitrile (96:4), the diluent was a mixture of $6.9 \mathrm{~g}$ of 
monobasic potassium phosphate with $1000 \mathrm{~mL}$ distilled water, adjusted with $45 \% \mathrm{NaOH}$ solution to a pH of $5.0 \pm 0.1$.

The standard solution was prepared by dissolving an accurately weighed quantity of the pharmaceuticals to be studied in diluents to obtain a solution having a known concentration of about $1.2 \mathrm{mg} / \mathrm{mL}$ (degassed by ultrasonication before use). The retention time and wavelength for each drug are shown in Table 1.

Table 1. Wavelengths and retention times for the pharmaceuticals using HPLC.

\begin{tabular}{lll}
\hline Drug name & Wavelength $(\mathbf{n m})$ & Retention time (min) \\
\hline Amoxicillin & 230 & 9.16 \\
Ibuprofen & 254 & 2.00 \\
Caffeine & 256 & 20.71 \\
\hline
\end{tabular}

\subsection{Calibration curves}

Standard calibration curves for amoxicillin, ibuprofen, and caffeine were made by preparing a stock solution containing $500 \mathrm{mg} / \mathrm{L}$ of ibuprofen, amoxicillin and caffeine as reference standards and then transferred into $100 \mathrm{~mL}$ volumetric flasks of $10,30,40,50$ and $60 \mathrm{mg} / \mathrm{L}$ of each compound. Absorbance readings were recorded at $254 \mathrm{~nm}$ for ibuprofen, $230 \mathrm{~nm}$ for amoxicillin, and at $256 \mathrm{~nm}$ for caffeine.

\section{Results and discussion}

\subsection{Soil tests}

Samples of red soil were analyzed in order to evaluate the soil texture, moisture, $\mathrm{pH}$ value, and specific gravity. Table 2 shows the results obtained from these tests.

From the table it was noticed that the silt percentage is larger than the clay and both organic carbon and organic matter were high which increased the adsorption capacity of drugs.

Table 2. Soil specific gravity, $\mathrm{pH}$, texture, and moisture for soil before pollution.

\begin{tabular}{ll}
\hline Soil properties & Result \\
\hline Specific gravity & 2.34 \\
pH & 7.14 \\
Clay, \% & 41 \\
Silt, \% & 71 \\
Moisture content, \% & 29 \\
Organic carbon, \% & 7.34 \\
Organic matter, \% & 10.36 \\
\hline
\end{tabular}

\subsection{Polluted leachate water from ibuprofen, amoxicillin, and caffeine analysis}

The leachate water that flowed from each soil column was kept in well closed High Density Polyethylene (HDPE) containers and stored in refrigerator at $7{ }^{\circ} \mathrm{C}$ and then analyzed by HPLC. The absorbance readings were recorded, and converted to concentrations (mg/L) using standard calibration curves. The results are shown in Figure 1-3 for the three drugs and this data represents the kinetic study for the leachate in one and 15 years, respectively.

From the results that have been obtained, the speed of flow of water in blank columns is much higher than in other columns with added medications because of the lack soil correlation with any other additives.

Hydrolysis of ibuprofen, amoxicillin, and caffeine in polluted water followed first order kinetics as prescribed in the plotted graphs (Figure 1, 2 and 3). Straight lines were obtained after plotting $\operatorname{Ln}[\mathrm{A}]$ vs. time and it agrees with previous studies [18-21].

As prescribed in Figure 2. The concentration measured of ibuprofen in polluted water was decreased among the one year and 15-years columns, due to the limited mobility of the compound and rapid degradation, and because the soil used in the experiment has a pH of 7.41. Ibuprofen dissolved in acidic media more than any other pharmaceuticals [18].

It was noted that amoxicillin concentrations decreased less dramatically and rapidly than ibuprofen due to its nature, as it decomposes during the first 6 hours of time [22]. While it was observed that the concentrations of caffeine were obviously larger than both ibuprofen and amoxicillin, this is because caffeine is a more water soluble compound [23].

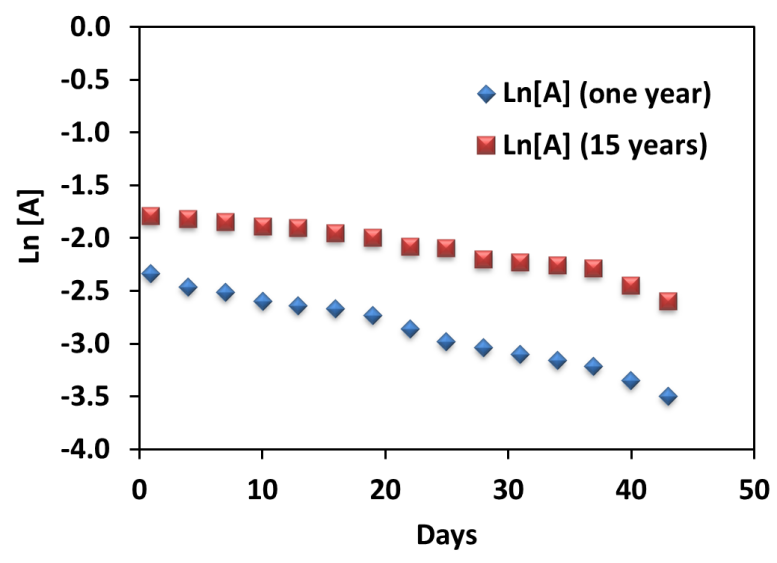

Figure 1. Ln $[\mathrm{A}]$ versus time for polluted water flowed from amoxicillin column for one and fifteen years.

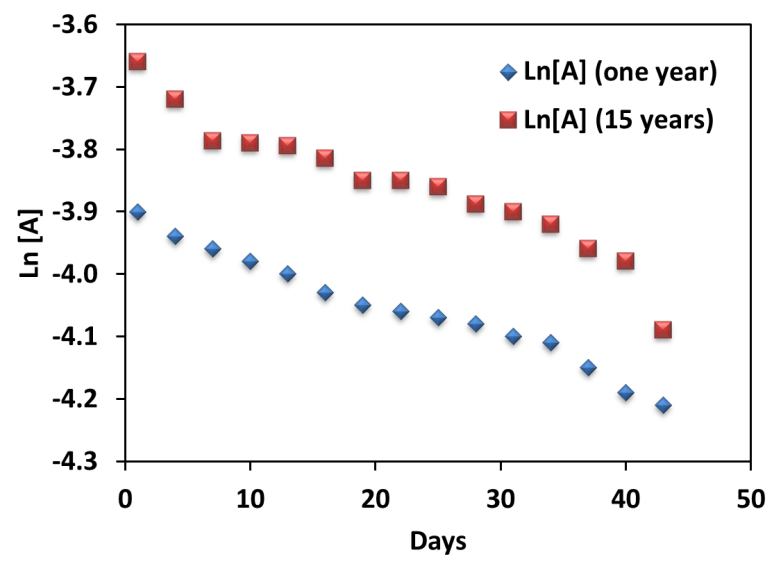

Figure 2. Ln $[\mathrm{A}]$ versus time for polluted water flowed from ibuprofen (oneyear and fifteen years).

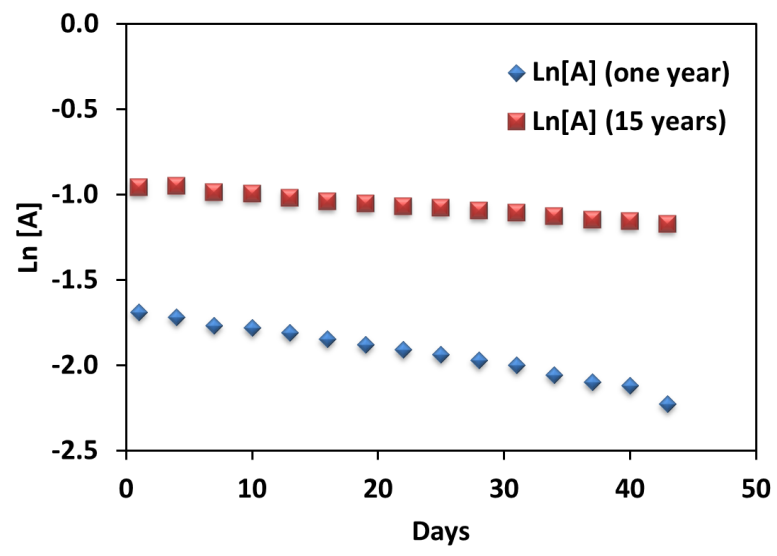

Figure 3. Ln $[A]$ versus time for polluted water flowed from caffeine (oneyear and fifteen years). 
Table 3. Mass balance for amoxicillin, ibuprofen and caffeine

\begin{tabular}{|c|c|c|c|}
\hline ( & $\begin{array}{l}\text { Total concentration in leachate } \\
\text { (mg/L)/ } 43 \text { days }\end{array}$ & $\begin{array}{l}\text { Total concentration adsorbed on soil } \\
(\mathrm{mg} / \mathrm{L}) / 43 \text { days }\end{array}$ & $\begin{array}{l}\text { Decomposed } \\
(\%)\end{array}$ \\
\hline $\begin{array}{l}\text { Amoxicillin one-year } \\
2150(\mathrm{mg} / \mathrm{L})\end{array}$ & 40.42 & 9.90 & 97.66 \\
\hline $\begin{array}{l}\text { Amoxicillin 15-year } \\
32,250(3.23 \%)\end{array}$ & 1213.46 & 706.92 & 94.04 \\
\hline $\begin{array}{l}\text { Ibuprofen one-year } \\
2150(\mathrm{mg} / \mathrm{L})\end{array}$ & 11.18 & 34.3 & 97.88 \\
\hline $\begin{array}{l}\text { Ibuprofen 15-year } \\
32,250(3.23 \%)\end{array}$ & 258.00 & 1161.00 & 96.60 \\
\hline $\begin{array}{l}\text { Caffeine one year } \\
2150(\mathrm{mg} / \mathrm{L})\end{array}$ & 96.75 & 38.70 & 93.70 \\
\hline $\begin{array}{l}\text { Caffeine 15-year } \\
32,250(3.23 \%) \\
\end{array}$ & 3010.00 & 1400 & 86.32 \\
\hline
\end{tabular}

\subsection{Distribution of pharmaceutical in soil columns after finishing the leachate study}

After finishing the leachate studies from the columns in one year and fifteen year studies, the columns were cut-off for 8 equal parts and a representative sample of soil was taken from each part as described in Section 2.2 to see the distribution of adsorption in each layer of the columns.

From the results of this part of study, the pharmaceuticals were distributed along the columns. Amoxicillin in one and fifteen years soil columns (Figure 4 and 5), showed the highest concentrations in the region of $0-25 \mathrm{~cm}$, and the amount of amoxicillin was rapidly decreased as increasing in soil depth, which was an indication of amoxicillin low mobility in soil due to its rapid degradation [22].

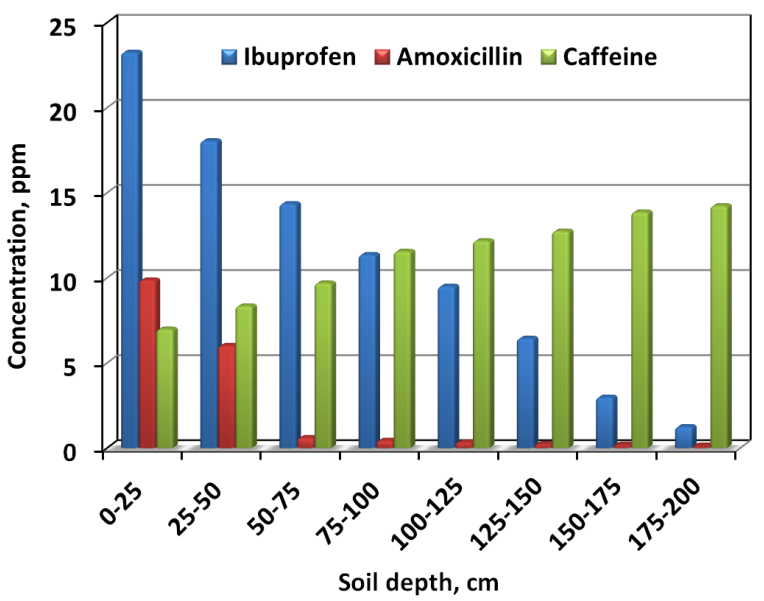

Figure 4. Amoxicillin, ibuprofen, and caffeine concentrations measured in soil layers for one year.

In Ibuprofen one year and fifteen years soil columns (Figure 4 and 5), the highest concentrations were found in the region of $0-25$ and $25-50 \mathrm{~cm}$, because it had both hydrophilic and hydrophobic features, so it can dissolve in water and adsorb on soil at the same time.

In Caffeine one and fifteen years columns (Figure 4 and 5), especially in the region of $150-175$ and $175-200 \mathrm{~cm}$, indicated a higher mobility of caffeine than ibuprofen and amoxicillin in soil. On the other hand, caffeine has higher solubility in water than others do [23].

\subsection{Mass balance}

The purpose from this process is accounting for pharmaceuticals entering and leaving a system, mathematically the mass balance for a system without a chemical reaction is as follows:
Input= Output + Accumulation

(1)

In our study we have the following equation:

Input $=$ Output $($ conc. in leachate $)+($ conc. adsorbed on soil $)+($ Decomposed materials)

The input of each drug per day was $50 \mathrm{mg} / \mathrm{L}$, and the total input for each drug in 43 days was $2150 \mathrm{mg} / \mathrm{L}$. Table 3 shows the mass balance for the pharmaceuticals drugs that we used in our study.

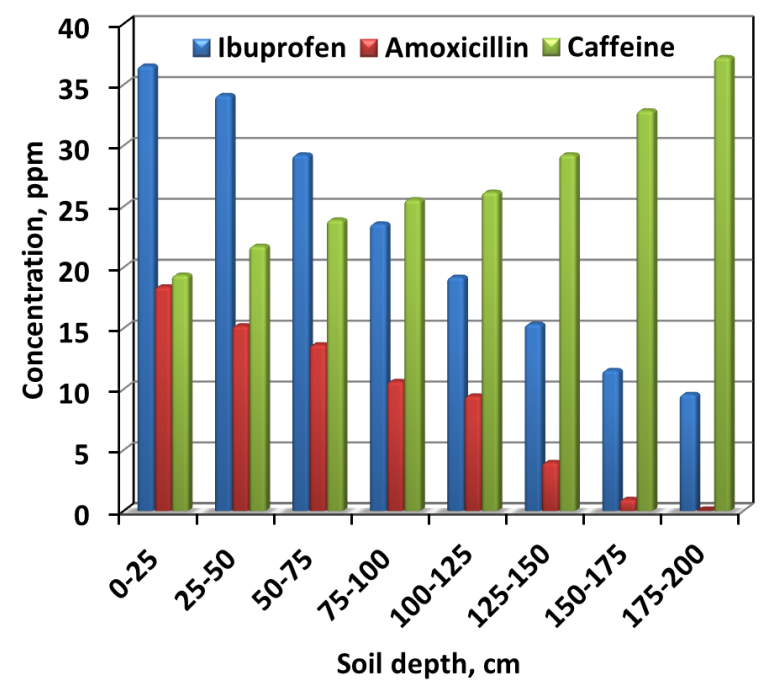

Figure 5. Amoxicillin, ibuprofen, and caffeine concentrations measured in soil layers for 15 years.

For amoxicillin its output was not of equal input because it's a very degradable compound and affects with biological and non-biological factors in soil and wastewater especially ammonia, phosphate and hydroxyl groups. All of these factors can participate in the reduction of amoxicillin level. Again in the case of ibuprofen it decomposed thermally producing many toxic products like 4-isobutlacetophenone which is a popular non-prescription drug that may entail prolonged use. It's used to monitor the presence of all degradation products and to study their long term toxicity [24].

For caffeine, it degrades within a few weeks and produces the $o$-bromine and the $o$-phylline compounds which are useful in the industrial world [25-26].

The results in Table 3 might be explained in two ways: First the life time of those pharmaceuticals are less than 5 hours. Secondly, whatever we got without degradation has been diluted due to daily addition of amoxicillin, ibuprofen and 
caffeine, in addition to the bacterial effect and that's why we got very small concentrations, less than $1 \mathrm{mg} / \mathrm{L}$ [27].

\section{Conclusion}

The adsorption characteristics of pharmaceuticals in soils and ground water are of great importance environmentally, because such processes are associated with the ecotoxicity, degradation, transportation, and bioaccumulation in the soil environment. Adsorption of ibuprofen, amoxicillin, and caffeine was studied using soil columns and the following results were obtained.

The leachate and equilibrium of ibuprofen, amoxicillin and caffeine were best described using first-order reaction and Freundlich isotherm. Ibuprofen concentration was decreased in leachates amongst the one year and 15-years columns. This was due to the soil passage acting as an effective barrier for ibuprofen, due to sorption and/or due to microbial degradation and this will affect its mobility.

Amoxicillin concentrations decreased dramatically and rapidly in leachate among the one year and 15-years columns, more than ibuprofen due to its nature as a high degradable compound.

Another observation was observed. The concentrations of caffeine were obviously larger than that in ibuprofen and amoxicillin amongst the one year and 15-years columns; this is because of that caffeine is more water soluble; despite it not reaching $1 \mathrm{mg} / \mathrm{L}$. During the columns' study the leachate from those columns was found to be less than $1.0 \mathrm{mg} / \mathrm{L}$ which means that there will be no environmental effects of those pharmaceuticals on the ground water nor are further studies required.

\section{Acknowledgement}

We would like to thank the Palestenian Universities Union for their financial support for this research. We also would like to thank Jerusalem Pharmaceuitical Company for letting us use their HPLC instrument.

\section{References}

[1]. Stegmann, R.; Christensen, T. H.; Cossu, R. Landfill leachate: an introduction, in: Landfilling of Waste: Leachate, pp. 3-14, Elsevier Applied Science, London and New York, 1992.

[2]. Bjerg, P. L.; Rugge, K.; Pedersen, J.; Christensen, T. H. Environ. Sci. Technol. 1995, 29, 1387-1394.

[3]. Hernando, M. D.; Mezcua, M.; Fernandez-Alba, A. R.; Barcelo, D. Talanta 2006, 69, 334-342.

[4]. Pico, Y.; Andreu, V. Anal. Bioanal. Chem. 2007, 387, 1287-1299.

[5]. Okuda, T.; Yamashita, N.; Tanaka, H.; Matsukawa, K.; Tanabe, A. Environ. Int. 2009, 35, 815-820.

[6]. Schroder, H. F. Waste Manage. 1999, 19, 111-123.

[7]. Toze, S. Agric. Water Manage. 2006, 80, 147-159.

[8]. Jimenez, B. Int. Rev. Environ. Strategies 2006, 4, 229-250.

[9]. Miller, K. D.; Husmann, H.; Nalik, H. P.; Schomburg, G. Chromatographia 1990, 30, 245-248.

[10]. Heberer, T.; Stan, H. J. Int. J. Environ. Anal. Chem. 1997, 67, 113-124.

[11]. Heberer, T.; Dunnbier, U.; Reilich, C.; Stan, H. J. Fresenius. Environ. Bull. 1997, 6, 438-443.

[12]. Nason, J. A. "Literature Review: Occurrence and Fate of Pharmaceutical Compounds in Landfill Leachate" Prepared for: Oregon Association of Clean Water Agencies, EPA Publisher, Washington D. C., U.S.A, 2007.

[13]. Kolpin, D. W.; Furlong, E. T.; Meyer, M. T.; Thurman, E. M.; Zaugg, S. D.; Barber. L. B. Environ. Sci. Technol. 2002, 36, 1202-1211.

[14]. Cordy, G. E.; Duran, N. L.; Bouwer, H.; Rice, R. C.; Furlong, E. T.; Zaugg, S. D.; Meyer, M. T.; Barber, L. B.; Kolpin, D. W. Ground Water Monit. R. 2004, 24, 58-69.

[15]. Andrew, D. E.; Lenore, S. C.; Arnold, E. G. Standard methods for the examination of water and wastewater, $19^{\text {th }}$ edition., American Public Health Association Publisher, Waldorf, Maryland, U.S.A, 1995

[16]. Anyakora, C. H.; Nwaeze, K.; Awodele, O.; Nwadike, C.; Arbabi, M.; Coker, H. J. Chem. Environ Ecotoxicol. 2011, 3, 25-31.

[17]. Dwivedia, A.; Dhar, G. K.; Rajeev, J. Chem. Eng. J. 2011, 168, 12791288.

[18]. Tang, K.; Cai, J.; Zhang, P. Ind. Eng. Chem. Res. 2011, 56, 964-971.
[19]. Navarro, P. G.; El Bekkouri, A.; Reinoso, E. R. Analyst. 1998, 123, 2263 2266.

[20]. Baek, M.; Ijagbemi, C. O.; Se-Jin, O.; Kim, D. J. Hazard. Mater. 2010, 176 820-828.

[21]. Le-Minh, N.; Khan, S. J.; Drewes, J. E.; Stuetz, R. M. Fate of antibiotics during municipal water recycling treatment processes, UNSW Water Research Center, School of Civil and Environmental Engineering, University of New South Wales, volume 44, Australia, 2010.

[22]. Lim, L.; Go, M. Eur. J. Pharm. Sci. 2000, 10, 17-28.

[23]. Caviglioli, G.; Valeria, P.; Brunella, P.; Sergio, C.; Attilia, A.; Gaetano, A. J. Pharm. Biomed. Anal. 2002, 30, 377-896.

[24]. Jacobs, L. E.; Fimmen, R. L.; Chin Y. Water 2011, 45, 4449-4458.

[25]. Sathyanarayana, N. G.; Bhavya, B.; Nandhini, A. J. Ind. Microbiol. Biotechnol. 2012, 93, 545-554.

[26]. Kakimoto, T.; Funamiz, N. Chemosphere 2007, 66, 2219-2224. 